\title{
Association between antenatal care utilization pattern and timely initiation of postnatal care checkup: Analysis of 2016 Ethiopian Demographic and Health Survey
}

Gizachew Tadesse Wassie ( $\sim$ leulgzat@gmail.com )

Bahir Dar University https://orcid.org/0000-0001-6213-0191

Minyichil Birhanu Belete

Bahir Dar University College of Medical and Health Sciences

Azmeraw Arega Tesfu

Bahir Dar University College of Medical and Health Sciences

Simachew Animen Bantie

Bahir Dar University College of Medical and Health Sciences

Asterey Assmie Ayenew

Bahir Dar University College of Medical and Health Sciences

Belaynew Adugna Endeshaw

Bahir Dar University College of Medical and Health Sciences

Semaw Minale Agdie

Bahir Dar University College of Medical and Health Sciences

Mengistu Desalegn Kiros

Bahir Dar University College of Medical and Health Sciences

Zelalem T Haile

Ohio University Heritage College of Osteopathic Medicine

Mohammad Rifat Haider

Ohio University

Gillian H Ice

Ohio University Heritage College of Osteopathic Medicine

Research article

Keywords: Postnatal care, Antenatal care, EDHS, Ethiopia

Posted Date: September 1st, 2020

DOI: https://doi.org/10.21203/rs.3.rs-66089/v1 
License: (c) (i) This work is licensed under a Creative Commons Attribution 4.0 International License. Read Full License 


\section{Abstract}

Background: Despite significant public health intervention, maternal mortality remains high in low- and middle-income countries, including Ethiopia. Effective postnatal care is a critical service to reduce maternal mortality. In Ethiopia, only $17 \%$ of mothers received postnatal care service in 2016 . This study examined the association between antenatal care and timely postnatal care checkup among reproductive age women in Ethiopia.

Methods: The study used the 2016 Ethiopian Demographic and Health Survey data. The sample consisted of 4,081 women who give birth within the last two years prior to survey. Chi-square test and multivariable logistic regression were used to examine the association between antenatal care and timely initiation of postnatal care.

Results: Postnatal care services within 2 days of delivery were received by $16.5 \%$ of women. Women who had at least four timely antenatal care visits had higher odds of timely postnatal checkup compared to women who had no antenatal care [adjusted Odds Ratio (aOR): $2.50 ; 95 \%$ Confidence Interval $(95 \% \mathrm{Cl})$ 1.42-4.42]. Women who had at least four antennal care visits without timely initiation also had higher odds of postnatal check-up than their counterparts (aOR: 2.46 ; $95 \% \mathrm{Cl}: 1.22-4.97$ ). Other factors significantly associated with timely initiation of PNC were secondary and above education (aOR: 1.64; 95\%Cl: 1.03-2.60), perceived distance to the nearby health facility as significant barrier (aOR: 1.55; 95\%Cl: $1.15-2.09$ ), primiparous (aOR: $0.34 ; 95 \% \mathrm{Cl}: 0.19-0.61$ ) and institutional delivery (aOR: 14.55; 95\%Cl: 2.21-95.77).

Conclusion: Timely initiation of postnatal care within two days of delivery in Ethiopia is very low. Women who received recommended antenatal care services had higher odds of timely initiation of postnatal care. Thus, strengthening the existing maternal and child health programs to adhere to the recommended ANC care guidelines may improve timely initiation of postnatal care.

\section{Introduction}

The postnatal period, defined as the first six weeks after birth, is critical to the health and survival of mother and newborn (1). The majority of maternal deaths, mainly due to hemorrhage, and many newborns deaths, mostly due to asphyxia, occur during the first day of birth $(2,3)$. Furthermore, lack of care during this period may result in disability as well as create missed opportunities for promoting healthy behaviors affecting women, newborns and children $(1,4)$.

Although global maternal deaths have decreased by $43 \%$ from 532,000 in 1990 to 303,000 in 2015(5), maternal morbidity and mortality remain a major challenge to health care systems. Worldwide, the maternal mortality rate is 216 per 100,000 live births with a large proportion of deaths due to early preventable or treatable pregnancy and childbirth complications. Low- and middle-income countries (LMIC) account for $99 \%$ of maternal deaths, with sub-Saharan African countries alone accounting for 
$66 \%(6,7)$. In Ethiopia, in 2016 the maternal mortality ratio (MMR) remains high with 412 maternal deaths per 100,000 live births (8).

In the continuum of maternal health care, antenatal care (ANC) and postnatal care (PNC) are the key strategies required to reduce the maternal and new-born deaths (9). ANC is an entry point for maternal and child care service utilization, and as such, has the capability of reducing both maternal and neonatal mortality by detecting at-risk pregnancy and managing the risk associated. ANC provides opportunity to adequately prepare mothers birth and for appropriate care of children by addressing relevant information and education concerning to promoting the health, prevention of disease (10). Therefore, all pregnant women are recommended to have their first ANC visit within the first trimester of pregnancy at or before 16 weeks of gestation and to have minimum four ANC visits during pregnancy (10). ANC is an important opportunity to identify and manage any medical complications (11). Globally $86 \%$ of pregnant women access ANC with skilled health personnel at least once and only $65 \%$ receive at least four ANC visits. Whereas, in sub-Saharan Africa only $52 \%$ and South Asia only $49 \%$ of women and had received at least four ANC visits (12). In Ethiopia, in 2016 only $62 \%$ of women had any ANC visits during pregnancy, $32 \%$ of women had at least four ANC visits, and only $20 \%$ of women had their first ANC visit during the first trimester (8).

The World Health Organization (WHO) recommends that mothers and newborns should receive PNC in health facilities within at least 24 hours after birth if birth occurs in a health facility. For home births, the first postnatal contact should be as early as possible within 24 hour of birth. Additionally, at least three postnatal visits, on day 3 (48-72 hours), between 7-14 days, and at six weeks after birth are recommended for all mothers and newborns (13). Safe motherhood programmers recommend that all women receive a health check within 2 days after delivery (8).

For both the mother and infant, early postnatal care is vital for providing essential information as well as detecting and treating childbirth-related complications. Most of the maternal and neonatal deaths occur during or immediately after childbirth $(1,8,14)$. Around half of the maternal and newborn deaths occur in the first 24 hours $(15,16)$. The majority of maternal deaths can be reduced through increasing antenatal care, skilled care during childbirth, emergency obstetric care and postnatal care services $(17,18)$. In Ethiopia, receiving appropriate postnatal care in the recommended time could avert neonatal mortality by $10-27 \%$ (14). However, in spite of its potential role in reducing newborn and maternal deaths, postnatal care has been poorly utilized for the health and survival of both the mother and the newborn (14). For instance in Ethiopia, only $17 \%$ of women and $13 \%$ of newborns received their postnatal checkup within the first two days of delivery (8).

Improving the quality of antenatal care services is likely to contribute to rapid increases in postnatal care utilization and results in better health outcomes for women and newborns (20). As a result, ANC utilization and timely initiation of PNC considered critical to maternal health services to improve health outcomes for women and newborns. The objective of this research was to determine the association between antenatal care and timely postnatal care checkup among reproductive age women in Ethiopia. 
We hypothesized that Ethiopian women who had timely and at least four ANC visits were more likely to have a timely PNC checkup.

\section{Methods}

\section{Study setting, design and period}

This study was a secondary data analysis of the 2016 Ethiopia Demographic and Health Survey (EDHS) which was collected by the Central Statistical Agency (CSA), Ethiopia and the DHS Program, ICF (8). The survey was conducted from January 18, to June 27, 2016. A detailed description of the 2016 EDHS study design and methods are available elsewhere (8). In brief, the 2016 EDHS participants included a stratified, two-stage cluster probability sample representative of the Ethiopian population. The sampling frame for the 2016 EDHS was the 2007 Ethiopian Population and Housing Census (PHC). In the first stage, a total of 645 enumeration areas (EAs) (202 from urban areas and 443 from rural areas) were selected out of the 84,915 EAs listed in the PHC based on probability proportional to EA size. This was followed by selection of 28 households from each EA from a new list of households prepared for all the selected EAs with an equal probability systematic selection. All women aged 15-49 and men aged 15-59 who were either permanent residents of the selected households or visitors, or who stayed in the household the night before the survey were eligible to be interviewed.

\section{Inclusion and exclusion criteria}

Of the total 15,683 women interviewed in the 2016 EDHS only those who give birth within the last two years prior to survey were included in this analysis $(n=4,308)$. Women who had missing data on the variables of interest were excluded from the analysis. The final sample included 4,081 (Fig. 1).

\section{Study variables}

The outcome variable was timely postnatal checkup, which was defined as receiving postnatal checkup within 2 days after delivery (8). The main exposure of interest was antenatal care (ANC) utilization. This was defined based on the WHO recommendations regarding the timing of first ANC attendance and total number of ANC attendance. As WHO recommends the first ANC visit should take place within the first trimester of gestation, and at least four visits during the course of the pregnancy (21). According to these guidelines, the exposure variable antenatal care use was categorized as: No ANC visit, 1-3 ANC visits but not started timely PNC, 1-3 ANC visits and started timely PNC, $\geq 4$ ANC visits and not started timely PNC, $\geq 4$ ANC visits and started timely PNC.

Additional covariates were examined included in the models, including socio-demographic and obstetric characteristics. Socio-demographic characteristics included maternal age at the time of birth of the most recent child, educational status, marital status, place of residence, current working status of the mother, 
and household wealth index. DHS uses principal component analysis technique to assign households wealth scores based on the number and kinds of consumer goods they own, ranging from a television to a bicycle or car, in addition to housing characteristics such as source of drinking water, toilet facilities, and flooring materials (8). Obstetric characteristics included type of birth attendant (skilled, unskilled), place of delivery (institutional, home), parity [primiparous (1), multiparous (2-4), and grand multiparous $(\geq 5)$ ], mother's perceived distance of the nearest health facility (problematic, non-problematic) and type of pregnancy (planned, unplanned).

\section{Statistical analysis}

Frequencies and percentages were used to describe socio-demographic characteristics of participants. Chi square tests were performed to check for factors that were associated with timely postnatal care utilization. Multiple logistic regression was performed to identify factors associated with timely postnatal care checkup. All independent variables were fitted into the multivariable logistic regression to control for confounding and identify the association between antenatal care and timely postnatal care. Adjusted Odds Ratio (aOR) with $95 \%$ Confidence Interval $(95 \% \mathrm{Cl})$ was reported. Multicollinearity was checked using variance inflation factor (VIF) with maximum threshold 4 and no multicollinearity was detected. Survey design elements including stratification, cluster and sampling weights were applied to account for complex survey design and unequal probabilities of selection. All analyses were performed using SPSS version 23 (22). P-value $<0.05$ were considered statistically significant.

\section{Results}

\section{Sample Characteristics}

The majority (87.7\%) of women lived in rural areas. Furthermore, $95.1 \%, 60.4 \%$ and $45.2 \%$ of women were married, had no formal education and lived in the poor wealth quintile, respectively. About $60.5 \%$ of women perceived that the distance to nearby health facility as a barrier to PNC utilization. Nearly half (42.2\%) of the women were multiparous (had two or more pregnancy). Only $36.9 \%$ of women gave the most recent birth in the health facility while $37.7 \%$ were served by skilled birth attendant. More than one third $(35.7 \%)$ of women did not have any ANC visits and only one-fourth $(25.1 \%)$ of women had the recommended four ANC visits with timely initiation (Table 1).

\section{Timely postnatal checkup}

Among women who gave birth in the two years before the survey, only $16.5 \%$ of women had timely initiated postnatal checkup within two days of delivery. Furthermore, postnatal checkup significantly differed by history of ANC follow-up, educational status, place of residence, working status, perceived distance from a nearby health facility, household wealth index, place of delivery and type of birth attendant (Table 2). 


\section{Association between antenatal care utilization pattern and timely postnatal checkup}

After controlling for all other variables, antenatal care use was significantly associated with timely postnatal care checkup. Women who had at least four ANC visits and that were timely initiated had higher odds of timely postnatal checkup in comparison with women with no ANC visit (aOR: $2.50 ; 95 \% \mathrm{Cl}$ : 1.42-4.42). Similarly, women who had at least four ANC visit but not timely initiated had higher odds of timely postnatal check-up in comparison with women with no ANC visit (aOR: 2.46; 95\% Cl: 1.22-4.97). Additionally, women who had secondary and above education (aOR: $164 ; 95 \% \mathrm{Cl}$ : 1.03-2.60) compared to those who had no education, those who perceived distance to the nearby health facility was not a significant barrier (aOR: $1.55 ; 95 \% \mathrm{Cl}: 1.15-2.09$ ) compared to those who perceived it as a significant problem, primiparous (aOR: $0.34 ; 95 \% \mathrm{Cl}$ : $0.19-0.61$ ) compared to grand multiparous, and those who had institutional delivery (aOR: $14.55 ; 95 \% \mathrm{Cl}: 2.21-95.77$ ) compared to those who had home delivery were also significantly associated with timely initiation of PNC checkup (Table 3 ).

\section{Discussion}

In a nationally representative sample of Ethiopian women, we found that having the recommended ANC visits were positively associated with timely utilization of PNC services. This association appeared to be independent of confounders such as maternal socio-demographic and obstetric characteristics. Our results contribute to the emerging evidence on the importance of having the recommended ANC on PNC utilization.

Women who started their first antenatal visit in the recommended timeframe and had at least four antenatal care visits were more likely utilize PNC than their counterparts. This finding is consistent with findings of several studies (23-29). Because ANC is a time when mothers are educated about childbirth and childcare practices, those who follow the ANC guidelines might be better informed about PNC guidelines. This assertion is supported through qualitative studies. Belachew et al. (2016) illustrated this point with the following focus group discussion quote, "I had repeated ANC visits during my previous two pregnancies and the health providers provided me cares such as complete physical assessment, I was given red tablets for free and told to swallow one per day, I was counseled about danger signs of

pregnancy and also I was told the benefits of institutional delivery and postnatal care. That is why I prefer to deliver my children in a health facility and I attended postnatal care...."page 6, (26). Increased numbers of antenatal visit might give opportunities to women to learn about birth preparedness, potential complications during pregnancy and labor(30). As a result, they might be more likely to follow recommendations, including recommended PNC protocol. 
Women who gave birth at health institution had higher odds of having timely PNC checkup compared to those women gave birth at home. This finding was consistent with other studies (18, 19, 21-26). Since all women who delivered at health facilities with an uncomplicated vaginal birth are expected to stay in the facility for at least 24 hours after birth, they are likely to receive PNC before discharge (33). Additionally, women may be advised to return for future visits and be more comfortable with the setting than those who deliver at home. Women who deliver at a facility also demonstrated ability to overcome cultural, geographic, financial and other barriers related to health care access (23).

Primiparous women were $66 \%$ less likely to utilize postnatal checkup timely as compared with multiparous women. This result was in line with previous studies $(20 ; 27)$. Previous experience with pregnancy complications may increase the likelihood of seeking post-natal care within 2 days to avoid similar complications. The fear associated with previous complications may compel women to seek regular care (32). Primiparous women, with no history to learn from, are therefore, less likely to have a fear of complications (26). In addition, this analysis found that the odd of having a timely PNC check-up was higher among women whose educational status was secondary/higher as compared to those with no education. This result was in line with a number of studies $(23-25,29)$. The more the maternal educational attainment, the more likely the awareness and knowledge of benefits to be derived to comply with more health recommendations; this is in part due to the fact that they may understand better. Additionally, women who are educated are more likely to have paid employment and to contribute to the household expenditure and consumption and that means more power in decision-making process in household issues including utilization of health services (28).

Mothers who did not perceive distance of the nearest health facility as a problem had higher odds of timely PNC checkup as compared to those who perceived distance to a health facility as a significant barrier. This was consistent with several previous studies $(23,25,35)$. Physical proximity to health services is a major problem, especially in rural villages with poor road conditions. Participants in a qualitative study complained that they needed to walk for up to two hours to reach the nearest health center. The situation became worse during the rainy season when the road was slippery (30). It is, therefore, not surprising that distance from a healthcare facility is a significant barrier to timely and recommended PNC utilization.

\section{Strength And Limitations Of The Study}

The main strengths of the study are the use of a nationally representative survey data and the availability of several potential confounders for adjustment in the multivariable regression model. Additionally, data were collected using a standardized questionnaire with rigorous procedures to check for data quality. However, this study has several limitations. As a secondary data analysis, some important variables were not included, such as role of husbands and other family members in maternal health decision making and cultural beliefs about when women are allowed to leave the house in postpartum period. Additionally, since women were asked retrospectively for their exposures, the response might be susceptible for recall bias. Furthermore, cross-sectional nature of the study does not allow for determination of causation. 


\section{Conclusions}

The initiation of postnatal care within two days of delivery in Ethiopia is very low. Utilizing the recommended number of ANC visits, starting it at early stage of pregnancy was positively associated with timely initiation of postnatal care. Even women, who had not initiated ANC in the recommended time frame but had had the recommended number of visits, had higher odds of appropriate PNC. Thus, strengthening the existing maternal and child health program to adhere to the recommended number of ANC is likely to improve adherence to PNC protocols.

\section{Abbreviations}

ANC

Antenatal Care

AOR

Adjusted Odds Ratio

$\mathrm{Cl}$

Confidence Interval

DHS

Demographic and Health Survey

EA

Enumeration Area

EDHS

Ethiopia Demographic and Health Survey

PNC

Post Natal Care

WHO

World Health Organization

\section{Declarations}

\section{Consent for publication}

Not applicable

\section{Competing interests}

The authors declare that they have no competing interests.

\section{Availability of data and materials}


The datasets used for this study are publicly available from the DHS Program website http://dhsprogram.com/data.

\section{Ethics approval and consent to participate}

Publicity available data set was obtained from the DHS website (https:// dhsprogram.com/) through registering with the DHS website and as such, no ethical approval was not required. This study was deemed exempt by the Ohio University Institutional Review Board.

\section{Funding}

This study was supported by an 1804 Grant from Ohio University.

\section{Authors' contributions}

GT, AA, SA and AA contributed in conceptualization of the study. MB, BA, SM and MD performed statistical analyses and literature review. GT, AA, SA, AA, MB, BA, SM, and MS prepared the initial draft. $\mathrm{ZH}, \mathrm{MRH}$, and $\mathrm{GI}$ supervised the conceptualization, statistical analyses, manuscript writing, and edited and prepared the final manuscript. All authors approved the final version of the manuscript.

\section{Acknowledgements}

We are grateful to the DHS Program for providing us permission to use the 2016 EDHS data for this analysis.

\section{References}

1. Mathai Matthews, von Xylander Severin and Zupan Jelka. (2010)WHO Technical consultation on postpartum and postnatal care. Geneva, October 29-31, 2008.

2. Ahmed I. Population-based rates, timing, and causes of maternal deaths, stillbirths, and neonatal deaths in south Asia and sub-Saharan Africa: a multi-country prospective cohort study. 2018;6:12.

3. Halim A, Dewez JE, Biswas A, Rahman F, White S, van den Broek N. When, Where, and Why Are Babies Dying? Neonatal Death Surveillance and Review in Bangladesh. PLoS ONE [Internet]. 2016 Aug 1 [cited 2020 Aug 24];11(8). Available from: https://www.ncbi.nlm.nih.gov/pmc/articles/PMC4968790/.

4. Warren C, Daly P, Toure L, Mongi P. Postnatal care. Oppor Afr Newborns Cape Town South Afr Partnersh Matern Newborn Child Health. 2006;79-90. 
5. Filippi V, Chou D, Ronsmans C, Graham W, Say L. Levels and Causes of Maternal Mortality and Morbidity. In: Black RE, Laxminarayan R, Temmerman M, Walker N, editors. Reproductive, Maternal, Newborn, and Child Health: Disease Control Priorities, Third Edition (Volume 2) [Internet]. Washington (DC): The International Bank for Reconstruction and Development / The World Bank; 2016 [cited 2020 Aug 25]. Available from: http://www.ncbi.nlm.nih.gov/books/NBK361917/.

6. World Bank Group, and United Nations Population Division Trends in Maternal Mortality. 1990 to 2015 Geneva: World Health Organization, 2015. Popul Dev Rev. 2016;42(4):726-6.

7. Alkema L, Chou D, Hogan D, Zhang S, Moller AB, Gemmill A. Global, regional, and national levels and trends in maternal mortality between 1990 and 2015, with scenario-based projections to 2030: a systematic analysis by the UN Maternal Mortality Estimation Inter-Agency Group. 2016.

8. Central Statistical Agency (CSA) [Ethiopia] and ICF. Ethiopia Demographic and Health Survey 2016. Maryland: CSA and ICF: Addis Ababa, Ethiopia, and Rockville; 2016.

9. Organization WH. Postpartum Care of the Mother and Newborn: a practical guide. Volth edition. Geneva: WHO; 1998.

10. Federal Ministry of Health (FMOH). [Ethiopia]. Management protocol on selected obstetrics topics. Addis Ababa: FMOH. January; 2010.

11. Tunçalp Ółzge, Pena-Rosas JP, Lawrie T, Bucagu M, Oladapo OT, Portela A, et al. WHO recommendations on antenatal care for a positive pregnancy experience-going beyond survival. BJOG. 2017;124(6):860-2.

12. UNICEF. Antenatal care [Internet]. UNICEF DATA. [cited 2020 May 25]. Available from: https://data.unicef.org/topic/maternal-health/antenatal-care/.

13. World Health Organization, Department of Maternal N Child and Adolescent Health. WHO recommendations on postnatal care of the mother and newborn [Internet]. 2013 [cited 2020 Mar 17]. Available from: http://www.ncbi.nlm.nih.gov/books/NBK190086/.

14. Information NC, for B, Pike USNL of M 8600 R, Usa MDB 20894. Executive summary [Internet]. WHO Recommendations on Postnatal Care of the Mother and Newborn. World Health Organization; 2013 [cited 2020 Mar 17]. Available from: https://www.ncbi.nlm.nih.gov/books/NBK190090/.

15. WHO. Postnatal Care for Mothers and Newborns Highlights from the World Health Organization 2013 Guidelines. 2015:1-8.

16. Ethiopian Federal Ministry of Health. Post-natal care. NICE Clinical Guideline. 2015:1-99.

17. Bustreo F, Say L, Koblinsky M, Pullum TW, Temmerman M, Pablos-Méndez A. Ending preventable maternal deaths: the time is now. Lancet Glob Health. 2013;1(4):e176-e7.

18. WHO. Strategies towards ending preventable maternal mortality (EPMM). 2015.

19. FDRE M. Postnatal Care Blended Learning Module for Health Extension program Ethiopia.

20. Determinants of Postnatal. Care Use in Kenya | Akunga | African Population Studies.

21. AbouZahr C, Wardlaw T. (2003). Antenatal care in developing countries: promises, achievements and missed opportunities-an analysis of trends, levels and differentials, 1990-2001. World Health 
Organization.

22. IBM Corp. Released 2015. IBM SPSS Statistics for Windows, Version 23.0. Armonk, NY: IBM Corp.

23. Rwabufigiri BN, Mukamurigo J, Thomson DR, Hedt-Gautier BL, Semasaka JPS. Factors associated with postnatal care utilisation in Rwanda: A secondary analysis of 2010 Demographic and Health Survey data. BMC Pregnancy Childbirth. 2016 May 31;16(1):122.

24. Khanal V, Adhikari M, Karkee R, Gavidia T. Factors associated with the utilisation of postnatal care services among the mothers of Nepal: analysis of Nepal Demographic and Health Survey 2011. BMC Womens Health. 2014 Dec;14(1):19.

25. Ayana Hordofa M. Postnatal Care Service Utilization and Associated Factors Among Women in Dembecha District, Northwest Ethiopia. Sci J Public Health. 2015;3(5):686.

26. Belachew T, Taye A. Postnatal Care Service Utilization and Associated Factors among Mothers in Lemo Woreda, Ethiopia. J Womens Health Care [Internet]. 2016 [cited 2020 Mar 17];5(3). Available from: http://www.omicsgroup.org/journals/postnatal-care-service-utilization-and-associated-factorsamong-mothersin-lemo-woreda-ethiopia-2167-0420-1000318.php?aid=74603.

27. Fekadu GA, Ambaw F, Kidanie SA. Facility delivery and postnatal care services use among mothers who attended four or more antenatal care visits in Ethiopia: further analysis of the 2016 demographic and health survey. BMC Pregnancy Childbirth. 2019 Feb;11(1):64. 19(.

28. Dahiru T, Oche OM. Determinants of antenatal care, institutional delivery and postnatal care services utilization in Nigeria. Pan Afr Med J [Internet]. 2015 [cited 2020 Mar 17];21(1). Available from: https://www.ajol.info/index.php/pamj/article/view/132573.

29. Bwalya BB, Mulenga MC, Mulenga JN. Factors associated with postnatal care for newborns in Zambia: analysis of the 2013-14 Zambia demographic and health survey. BMC Pregnancy Childbirth. 2017 Dec 13;17(1):418.

30. Islam S, Perkins J, Siddique MAB, Mazumder T, Haider MR, Rahman MM, et al. Birth preparedness and complication readiness among women and couples and its association with skilled birth attendance in rural Bangladesh. PLOS ONE. 2018 Jun;7(6):e0197693. 13(.

31. Wudineh KG, Nigusie AA, Gesese SS, Tesu AA, Beyene FY. Postnatal care service utilization and associated factors among women who gave birth in Debretabour town, North West Ethiopia: a community- based cross-sectional study. BMC Pregnancy Childbirth. 2018 Dec;27(1):508. 18(.

32. Limenih MA, Endale ZM, Dachew BA. Postnatal Care Service Utilization and Associated Factors among Women Who Gave Birth in the Last 12 Months prior to the Study in Debre Markos Town, Northwestern Ethiopia: A Community-Based Cross-Sectional Study [Internet]. Vol. 2016, International Journal of Reproductive Medicine. Hindawi; 2016 [cited 2020 Mar 17]. p. e7095352. Available from: https://www.hindawi.com/journals/ijrmed/2016/7095352/.

33. WHO, Department of Maternal N Child and Adolescent Health. WHO recommendations on postnatal care of the mother and newborn [Internet]. 2013 [cited 2020 May 27]. Available from: http://www.ncbi.nlm.nih.gov/books/NBK190086/. 
34. Mosiur Rahman M, Haque SE, Sarwar Zahan M. Factors affecting the utilisation of postpartum care among young mothers in Bangladesh. Health Soc Care Community. 2011;19(2):138-47.

35. 10.1186/1471-2393-10-61

Titaley, et al. Why don't some women attend antenatal and postnatal care services?: a qualitative study of community members' perspectives in Garut, Sukabumi and Ciamis districts of West Java Province, Indonesia | SpringerLink [Internet]. [cited 2020 Mar 17]. Available from: https://link.springer.com/article/10.1186/1471-2393-10-61.

\section{Tables}


Table 1

Descriptive statistics of women who gave birth in the 2 years before the survey, Ethiopia, 2016 DHS $(\mathrm{N}=4081)$

\begin{tabular}{|c|c|}
\hline Characteristics & n(weighted\%) \\
\hline \multicolumn{2}{|l|}{ Mother's age } \\
\hline $15-19$ & $275(6.4)$ \\
\hline $20-34$ & $2990(73.6)$ \\
\hline$\geq 35$ & 755 (20.0) \\
\hline \multicolumn{2}{|l|}{ Marital status } \\
\hline No & $198(4.9)$ \\
\hline Yes & 3822 (95.1) \\
\hline \multicolumn{2}{|l|}{ Education } \\
\hline No & $2383(60.4)$ \\
\hline Primary & 1115 (30.6) \\
\hline Secondary or above & $522(9.0)$ \\
\hline \multicolumn{2}{|l|}{ Place of residence } \\
\hline Urban & $829(12.3)$ \\
\hline Rural & 3191 (87.7) \\
\hline \multicolumn{2}{|l|}{ Working status } \\
\hline No & 3005 (75.0) \\
\hline Yes & $1015(25.0)$ \\
\hline \multicolumn{2}{|l|}{ Wealth Index } \\
\hline Poor & 2081 (45.2) \\
\hline Middle & $553(20.6)$ \\
\hline Rich & $1386(34.2)$ \\
\hline \multicolumn{2}{|c|}{ Perceived distance barrier the nearby health facility } \\
\hline Not significant barrier & $1849(39.5)$ \\
\hline Significant barrier & $2171(60.5)$ \\
\hline \multicolumn{2}{|l|}{ Type of pregnancy } \\
\hline Unwanted & $220(8.5)$ \\
\hline
\end{tabular}




\begin{tabular}{|cc|}
\hline Warity/birth order & $3800(91.5)$ \\
\hline Primiparous/1 & $870(20.3)$ \\
\hline Multiparous/2-4 & $1758(42.2)$ \\
\hline Grand multiparous/5+ & $1392(37.4)$ \\
\hline Place of Delivery & \\
\hline Home & $2348(63.1)$ \\
\hline Health Institution & $1672(36.9)$ \\
\hline Type of birth attendant & $2302(62.3)$ \\
\hline Unskilled & $1718(37.7)$ \\
\hline Skilled & $1332(35.7)$ \\
\hline ANC follow-up status and time of initiation \\
\hline No & $729(20.6)$ \\
\hline $1-3$ not started timely & $485(10.6)$ \\
\hline $1-3$ started timely & $315(8.0)$ \\
\hline$\geq 4$ not started timely & $1156(25.1)$ \\
\hline$\geq 4$ started timely & \\
\hline
\end{tabular}


Table 2

Characteristics of the study sample by postnatal checkup within 2 days of delivery ( $N=4081$ )

\begin{tabular}{|c|c|c|c|}
\hline \multirow[t]{3}{*}{ Characteristics } & \multicolumn{3}{|c|}{ Timely postnatal check-up } \\
\hline & Yes & No & $\mathrm{p}-$ \\
\hline & $\begin{array}{l}\mathrm{n} \text { (Weighted } \\
\%)\end{array}$ & $\begin{array}{l}\mathrm{n} \text { (Weighted } \\
\%)\end{array}$ & \\
\hline Mother's age & & & 0.288 \\
\hline $15-19$ & $62(1.0)$ & $213(5.4)$ & \\
\hline $20-34$ & $628(12.7)$ & $2362(60.9)$ & \\
\hline$\geq 35$ & $135(2.8)$ & $620(17.1)$ & \\
\hline Marital status & & & 0.769 \\
\hline No & $50(0.9)$ & $148(4.0)$ & \\
\hline Yes & 775 (15.7) & 3047 (79.5) & \\
\hline Education & & & $<0.001$ \\
\hline No Education & $296(6.3)$ & $2087(54.1)$ & \\
\hline Primary & $299(6.3)$ & $816(24.2)$ & \\
\hline Secondary or above & $230(3.8)$ & $292(5.1)$ & \\
\hline Residence & & & $<0.001$ \\
\hline Urban & $371(5.5)$ & $458(6.7)$ & \\
\hline Rural & $454(11.0)$ & $2737(76.8)$ & \\
\hline Working status & & & 0.001 \\
\hline No & $553(11.1)$ & $2452(64.0)$ & \\
\hline Yes & $272(5.4)$ & 743 (19.5) & \\
\hline Wealth Index & & & $<0.001$ \\
\hline Poor & $213(4.1)$ & $1868(41.2)$ & \\
\hline Middle & $100(2.8)$ & $453(17.7)$ & \\
\hline Rich & $512(9.6)$ & $874(24.6)$ & \\
\hline $\begin{array}{l}\text { Perceived distance barrier to the nearby health } \\
\text { facility }\end{array}$ & & & $<0.001$ \\
\hline Not significant barrier & $567(10.5)$ & $1282(29.0)$ & \\
\hline Significant barrier & $258(6.0)$ & $1913(54.5)$ & \\
\hline
\end{tabular}


Unwanted

Wanted

Parity/birth order

Primiparous/ 1

Multiparous/2-4

Grand multiparous/5+

Place of Delivery

Home

Health Institution

Type of birth attendant

Unskilled

Skilled

ANC follow up status and time of initiation

No

1-3 not started timely

1-3 started timely

$\geq 4$ not started timely

$\geq 4$ started timely
$41(1.2)$

$784(15.3)$

179 (7.3)

$3016(76.2)$

$<0.001$

255 (4.2)

$376(8.0)$

$194(4.4)$

$<0.001$

$41(0.9)$

784 (15.6)

2307 (62.1)

888 (21.3)

$<0.001$

$37(0.9)$

788 (15.6)

2265 (61.3)

930 (22.1)

$<0.001$

$46(1.3)$

1286 (34.4)

129 (2.8)

600 (17.8)

116 (2.0)

369 (8.6)

$80(2.2)$

235 (5.8)

454 (8.2)

705 (16.9) 
Table 3

Association between ANC follow up pattern and timely postnatal checkup ( $\mathrm{N}=4081$ )

Variables

Unadjusted $\mathrm{OR}^{\star}(95 \%$

$\mathrm{Cl} \bigotimes)$ $\stackrel{p-}{\text { Value }}$

Adjusted OR (95\%

$\mathrm{Cl})$

p-

Value

Mother's age

$15-19$

$1.08(0.66,1.77)$

0.757

$1.66(0.80,3.46)$

0.172

20-34

$1.28(0.94,1.68)$

0.127

$1.20(0.73,1.96)$

0.477

$\geq 35$

1.00

1.00

\section{Marital status}

No

1.00

1.00

Yes

$0.91(0.74,1.54)$

0.726

$0.89(0.52,1.51)$

0.657

\section{Education}

No

1.00

1.00

Primary

$2.21(1.67,2.92)$

$<0.001$

$1.33(0.93,1.90)$

0.119

Secondary and above

$6.28(4.43,8.89)$

$<0.001$

$1.64(1.03,2.60)$

0.036

Place of residence

Urban

$5.72(4.21,7.76)$

$<0.001$

$1.15(0.76,1.74)$

0.508

Rural

1.00

1.00

Working status of the

Mother

No

1.00

1.00

Yes

$1.63(1.24,2.14)$

$<0.001$

$1.01(0.74,1.37)$

0.963

Wealth Index

Poor

1.00

1.00

Middle

$1.69(1.16,2.47)$

$<0.006$

$1.07(0.66,1.74)$

0.779

Rich

$3.92(2.91,5.28)$

$<0.001$

$1.03(0.69,1.52)$

0.897

Perceived distance barrier to the nearby health facility

Not significant barrier

$3.24(2.54,4.13)$

$<0.001$

$1.55(1.15,2.09)$

0.004

Significant barrier

1.00

1.00

Type of pregnancy 


\begin{tabular}{|c|c|c|c|c|}
\hline Unwanted & 1.00 & & 1.00 & \\
\hline Wanted & $1.23(0.77,1.95)$ & 0.387 & $0.78(0.43,1.48)$ & 0.469 \\
\hline \multicolumn{5}{|l|}{ Parity/birth order } \\
\hline Primiparous(1) & $1.94(1.38,2.71)$ & $<0.001$ & $0.34(0.19,0.61)$ & $<0.001$ \\
\hline Multiparous (2-4) & $1.77(1.36,2.31)$ & $<0.001$ & $0.73(0.48,1.12)$ & 0.153 \\
\hline $\begin{array}{l}\text { Grand multiparous } \\
(\geq 5)\end{array}$ & 1.00 & & 1.00 & \\
\hline \multicolumn{5}{|l|}{ Place of Delivery } \\
\hline Home & 1.00 & & 1.00 & \\
\hline Health Institution & $49.23(28.83,84.14)$ & $<0.001$ & $14.55(2.21,95.77)$ & 0.005 \\
\hline \multicolumn{5}{|l|}{ Type of birth attendant } \\
\hline Unskilled & 1.00 & & 1.00 & \\
\hline Skilled & $38.75(23.52,63.85)$ & $<0.001$ & $2.54(0.37,17.56)$ & 0.344 \\
\hline \multicolumn{5}{|c|}{ ANC follow up status and time of initiation } \\
\hline No & 1.00 & & 1.00 & \\
\hline 1-3 not started timely & $3.92(2.34,6.57)$ & $<0.001$ & $1.48(0.82,2.66)$ & 0.197 \\
\hline 1-3 started timely & $5.54(3.16,9.70)$ & $<0.001$ & $1.74(0.86,3.53)$ & 0.124 \\
\hline$\geq 4$ not started timely & $8.55(4.68,15.57)$ & $<0.001$ & $2.46(1.22,4.97)$ & 0.012 \\
\hline$\geq 4$ started timely & $12.04(7.38,19.62)$ & $<0.001$ & $2.50(1.42,4.42)$ & 0.002 \\
\hline
\end{tabular}

\section{Figures}


There were total of $=84,915$ EAs

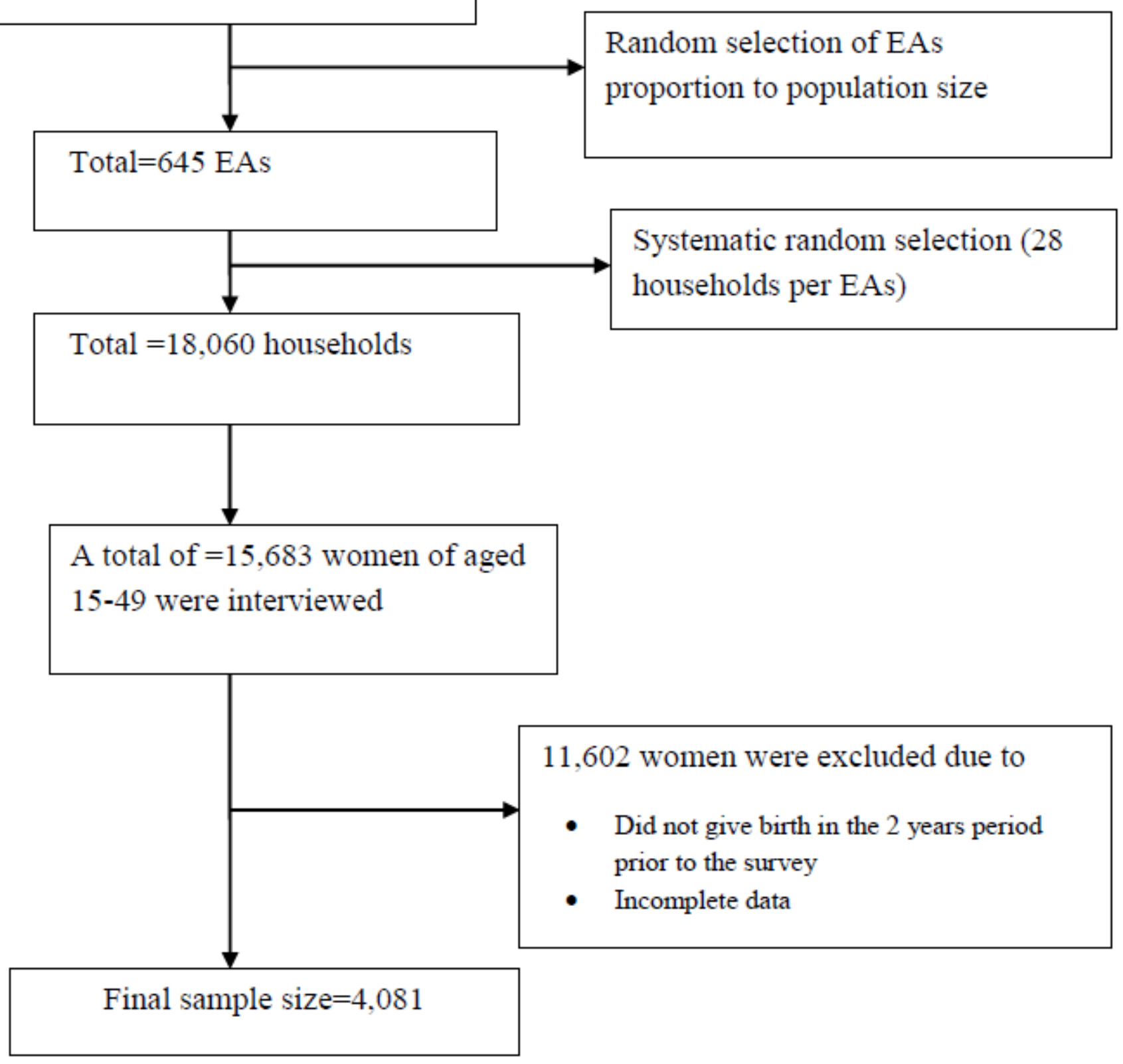

Figure 1

Schematic presentation of sample selection from EDHS 2016 data set. 